\section{Ambivalent sexist attitudes of young adolescents from the province of Jaén: Regarding the use of sexual and/or pornographic content on the} internet

\author{
María José Calero*, Ana Raquel Ortega Martínez and José \\ Luis Castillo Galán
}

University of Jaén, C/Antonio Martínez, 10, Villargordo (Jaén), CP 23630. España, Spain

\section{Abstract}

Knowing the possible origin of sexist attitudes in adolescents is essential when educating them to avoid gender violence derived from them. Nurses have an important role in education for the health of children and adolescents, so we must study the risk factors that lead to these attitudes and how to prevent them. Some studies such as Landripet, et al. have undertaken to study the association between frequency of pornography use and preference for violent and coercive content in male adolescents. Sexism and pornography use have been associated by various authors. Hostile sexism is the most obvious and traditional form, based on the supposed inferiority or difference of women as a group. According to benevolent sexism, women are understood as deserving of affection, respect and protection, as long as they are limited to certain traditional feminine roles. The second is even more difficult to detect. Our aim in this work is to evaluate ambivalent sexist attitudes in young adolescents in the province of Jaén and check whether there is a relationship between use of pornography and sexual content, and the kinds of sexism studied, in order to be able to prevent these attitudes as nurses through health education. The final sample was made up of 150 participants from all school years, belonging to the same secondary school, 74 male and 76 female. They were aged between 12 and 18 years old. One of the conclusions of this work has been that the use of new technologies is in addition starting at even younger ages due to the situation of online teaching due to the pandemic, and it has been observed that age at first use is a determining factor.

\section{More Information}

*Address for Correspondence: María José Calero, University of Jaén, C/Antonio Martínez, 10, Villargordo (Jaén), CP 23630. España, Spain, Tel: +34 647627845; Email:mjcalero@ujaen.es

Submitted: March 15, 2021 Approved: March 25, 2021 Published: March 26, 2021

How to cite this article: Calero MJ, Martínez ARO, Galán JLC. Ambivalent sexist attitudes of young adolescents from the province of Jaén: Regarding the use of sexual and/or pornographic content on the internet. Clin J Nurs Care Pract. 2021; 5: 024-030.

DOI: 10.29328/journal.cjncp.1001033

ORCiD: orcid.org/0000-0003-3960-1543

Copyright: @ 2021 Calero MJ, et al. This is an open access article distributed under the Creative Commons Attribution License, which permits unrestricted use, distribution, and reproduction in any medium, provided the original work is properly cited.

(D) Check for updates

OPEN ACCESS

\section{Introduction}

Children and adolescents are growing up in a digital world, with rapid expansion and development of ever more accessible phone and internet use. Therefore, adolescents are absorbed in the use of technology, a behaviour which is increasingly common in younger children [1]. Pornography has been around for a long time, and can be defined as the obscene nature of some literary and artistic works which seek the sexual excitation of the person looking at them. It can be found in different disciplines such as cinema, photography, literature, etcetera [2]. Since the arrival of the internet in modern society, most people have access to content of a sexual nature online. This (sexually explicit) material is available free of charge and is usually very popular in populations, with some websites like Pornhub which offer this content reaching 28.5 billion visits in 2017 [3] and being very easy to access [4]. According to Forbes magazine, this industry moves millions of dollars a year, which is why the magnates of this industry do not want to lose customers, regardless of their age [2]. Thus, online pornography has become content which is easily accessible and readily available for adolescents [5,6], the internet is not interested in understanding age [2]. In addition to adolescents, there is increasing childhood exposure to pornography which suggests this exposure could be harmful to these children, and which poses problems of a legal nature in light of the international legal framework which obliges most nations to create a national legal framework to protect and look after children [7]. 
Sexual experiences which take place online, whether the use of pornography, a sex chat, the use of sexualised social networks or the exchange of naked images, give rise to a new context for sexual socialisation. Due to lack of research, it is not known for certain whether these kind of experiences lead to sexual health problems or violent outcomes [8]. Pornography, as well as other content such as music videos broadcast on television, provokes greater acceptance of the rape myth in adulthood in children who view them more regularly, compared to those who do not, according to a study by Vangeel, et al. [9].

Pornography is used irrespective of gender, although male use dominates [10-14]. The purpose of such use is usually masturbation, with a positive physical, but not psychological, impact in terms of satisfaction, both for oneself and for couples who use it [10]. It can also be used to learn about the sexual organs and functions, the mechanics of sex, about performance and sexual roles and how sex should feel in terms of pleasure and pain [11], in addition to being a means of distraction, stimulation for a couple before sex (education/information as already stated), relieving stress or sexual frustration and exploring fantasies [15]. The lack of, or poor quality, sex education in students negatively affects adolescents when addressing their own sexuality, since as previously stated, access to this kind of content seeks to answer their questions about sexuality [2].

Pornography allows behaviours and roles which stereotype male and female genders, representing women as subservient to men at work (the man is the executive, while the woman is the secretary), and subjecting women to the sexual needs of men. The traditional sexual structure of sex between consenting adults is broken with, and only pleasure unrelated to love is sought. There are many risk behaviours shown in this type of content, such as not using condoms, sex with multiple partners, extra-vaginal sex, facial ejaculation, etc. [1].

Exposure to pornography has generally been associated with violence in adolescent dating and with sexual assault, but there is a lack of knowledge about violent pornography specifically [16]. This is a potential health problem, if we are talking about addiction, paraphilia and sexual disorders [17]. In addition, it may decrease satisfaction in a couple and in relationships, mainly due to issues of comparison, reduction in commitment due to visualising more attractive alternatives to the relationship, and increasing acceptance of infidelity [18].

Some studies such as Landripet, et al. have undertaken to study the association between frequency of pornography use and preference for violent and coercive content in male adolescents, obtaining the results that this preference decreases with time and there was no increase in the use of this type of pornography by increasing pornography use [5].
"The use of online pornography allows people to accumulate an encyclopaedic personal 'learning' whilst it also tends to confirm their orientation towards 'normal' sexual practices, and reproduce gender stereotypes", that is, it serves as a defensive weapon allowing judgement of what is normal and permissible in the panorama of erotic content available on the internet [19]. Not only pornography and erotic content, but also the frequency of exposure to women's lifestyle magazines or to reality shows, where women are objectified, if we associate them with pornographic content, predict more marked attitudes which support violence towards women [20].

There is a movement known as \#MeToo, which appeared after a series of sexual harassment scandals in Hollywood, a movement which received many complaints from politicians, columnists, etc., suggesting that the victims are "often" partly responsible for this harassment. This kind of statements can be related to the acceptance of rape myths, which are defined as "prejudicial, stereotyped or false beliefs about rape, rape victims, and rapists" and communication media may be contributing to these myths. The role of media therefore becomes very important regarding the development of sexist beliefs in adolescents, more precisely, beliefs about different measures to combat sexism such as the \#MeToo movement, a movement which may be criticised due to sexual objectification, which is fed by sexually explicit material online [21].

Regarding the age of first use of pornography, this varies greatly depending on the information obtained, that is, according to the type of study, region, etc. In some cases, the average age of first use of this material was 18.6 years old [3]. In Australia, there is a study which confirms that $100 \%$ of men surveyed in the study had viewed pornography and $82 \%$ of women as well, with the average viewing age being 13 in the case of men and 16 in the case of women. According to this study, $84 \%$ of young men and $19 \%$ of young women watch pornography weekly or daily, and data does not vary significantly in other studies. It also reflects a 79\% increase in pornography use in young Australians in the early 2000s [11]. In a US study, between 20 and $30 \%$ of young people had been exposed to pornography at between 10 and 12 years old [15]. In Italy, for example, a study was carried out where $77.9 \%$ of those surveyed (1163) admitted to having used pornography, $8 \%$ daily, with $59 \%$ using it purely for stimulation purposes [17]. In Canada, a study discusses a use of $85 \%$ in boys and an increasing use in girls, with an average age of first use of 12 years old [4]. But in order to be more exact, we should focus on more populations.

According to a US study, age was not a moderating factor, since use of pornographic material was associated with a comparable probability of sexual assault in both adults and adolescents. These sexually aggressive scripts are affected by pornography use due to repeated exposure, although the 
majority of this study's sample were university students or young people of this age [22].

Within use, studies such as Davis, et al. report that men have greater probability of reporting they have seen content with heterosexual anal sex, ejaculation in the woman's face, women portrayed as dominating, insults and violence towards a man which appears to be consensual [23]. Mainly amateur, oral and anal sex, and threesomes [15]. In addition, men who use this type of pornography claim wanting or having had certain behaviours such as hair pulling, whipping hard enough to leave a mark, facial ejaculation, restraint, double penetration (anal and vaginal at the same time), anal penetration followed by oral sex, gagging during fellatio, slaps in the face, asphyxia and insults [13].

For years, society has been concerned about increased use and convenience, regarding a possible link between sexually explicit material and different sexual behaviours (such as sexual satisfaction, sexist attitudes, body satisfaction and public health), suggesting that early exposure may drive or influence to a large degree certain affective, cognitive and behavioural factors in sexual matters [3]. Pornography use, especially violent pornography, but also non-violent pornography, desensitises viewers, increasing the incidence of negative attitudes towards women as well as towards sexuality [15]. Consequently, people who use these contents more frequently have greater probability of having attitudes which lead to sexual assault, and participating in acts of this kind, than those who do not use this content, or who do so to a lesser extent [22]. In addition, some men who use pornography show significantly higher adverse sexual beliefs, accept the rape myth and sexual conservatism, in greater measure than women who also consume pornography $[10,21]$. Thus increased research demonstrates that exposure to sexually explicit and violent media may be risk factors regarding partner violence and sexual violence [24]. The more pornography is used, the greater the probability of asking a partner for specific pornographic sexual acts, that is to say, "what happens on the screen may implicate life off of it" [25]. Therefore, when viewing aggressive and sexist behaviours and acts in pornography, it may be that attitudes which support these behaviours are adopted, as well as representing them in reality [18].

In one study, Binford concluded that a wide variety of studies carried out since 1995 suggest there is a relationship between a variety of problems and the exposure of children to pornography, including sexually permissive attitudes, regressive points of view towards women, an increase in the probability of men sexually assaulting women and victimization of women [7]. In addition to permissive attitudes, we should also mention more strongly stereotyped gender beliefs and greater experience with casual sexual behaviour [14]. Thus, as we have seen in the previous study, and as Landripet, et al. show in their study, sexual assault is not the only prejudicial result which should be associated with pornography. Many of the people studied report one or several associations between the use of this type of material and different adverse outcomes such as lower body selfesteem or sexual satisfaction and risk (5).

The most common behaviours seen in pornography establish a sexual script which focuses overwhelmingly on masculine pleasure and sexual desire, ignoring feminine pleasure and sexual desire [26]. Therefore, perceiving pornography as realistic is linked to more permissive sexual attitudes, in contrast to those who perceive it to be unrealistic [27]. Acts such as female anal sex, forced oral sex, men spitting on women are being normalized in pornographic videos viewed online, which may lead to them being imitated by viewers [26].

For some authors, religion may act as a mitigating factor, while pornography acts as a contributing factor in victimisation for sexual assault through risky sexual behaviour and scripts. Reference is made to other factors such as low sexual self-esteem, which is identified as a specific vulnerability factor in sexual victimisation, and that attitudes towards sexual coercion have been established as a specific predictor of sexual assault perpetration [28]. Ultimately, religion is a factor which may influence these behaviours and actions, but there is nothing to demonstrate a direct relation, which is why the interaction between religiousness and parental control in countries of a strongly religious nature should be studied, since religion is not always a protective factor in the adolescent's sexuality [29].

Regarding previous exposure to spousal abuse in parents, if we relate this with exposure to violent pornography, some authors confirm that this relation is very strong regarding the emergence of perpetration of sexual violence. It is suggested in their study that several malleable factors, such as interpersonal violence on young people from abusive parents, in addition reinforced by the use of violent pornography, may be risk factors in light of these actions by young people [30].

If in addition we separate the two genders, Whitney, et al. concluded in their study that exposure to violent pornography was associated with all types of violence during adolescent dating, but this pattern varied according to gender. Boys who used violent pornography were 2 to 3 times more likely to report sexual and physical perpetration and victimisation in violence during adolescent dating, whilst in girls, it was 1.5 times more probable than for girls who were not exposed to this content [16]. Furthermore, exposure to sexually explicit and violent material had a stronger impact on attitudes and behaviours related to partner violence and sexual violence in men who used this type of material than women who also used it [24]. Regarding women who use pornography, they have positive, mixed and negative experiences linked to the 
viewing [31] and in those who frequently use pornography, a study by Lim associates this with having had anal sex, some recounting pleasure and some recounting that it is more pleasurable for men. Some women had even been pressured or obliged to have this kind of sex which they had seen in pornographic material. In this study, this association was found in women but not in men, which establishes as a hypothesis that this is because women who are interested in learning about different sexual practices and anal sex are more likely to watch pornography, as well as that women who watch pornography are more likely to think that their partners would expect to have anal sex with them [11]. There is a study which shows that abused adolescents who participate in online sexual experiences are at greater risk of sexual victimisation [8].

Sexism and pornography use have been associated by various authors. But according to the theory of ambivalent sexism [32], it is necessary to distinguish between two kinds of sexism which co-exist in gender ideology: hostile sexism and benevolent sexism. Hostile sexism is the most obvious and traditional form, based on the supposed inferiority or difference of women as a group. According to benevolent sexism, women are understood as deserving of affection, respect and protection, as long as they are limited to certain traditional feminine roles. The second is even more difficult to detect.

Our aim in this work is to evaluate ambivalent sexist attitudes in young adolescents in the province of Jaén and check whether there is a relationship between use of pornography and sexual content, and the kinds of sexism studied.

\section{Method}

A descriptive study was carried out, where ambivalent sexist attitudes in young students in a secondary school public in the mountains south of Jaén were evaluated, and data on pornography use, sexual habits and the age of first experiences was collected.

\section{Participants}

The final sample was made up of 150 participants from all school years, belonging to the same secondary school, 74 male and 76 female. They were aged between 12 and 18 years old, with an average age of 14.83 .

\section{Procedure}

Data collection was carried out in the SCIENCES project 2019 , where 8 students from the centre worked on this topic, together with their teacher and the researchers. To collect the data, a questionnaire was used where in addition to their socio-demographic data (age, school year, sex), they were asked to indicate their age the first time they used a personal mobile phone, computer and viewed sexual content. In order to evaluate ambivalent sexism, the "Escala de detección de sexismo en adolescentes (DSA)" (Scale for detecting sexism in adolescents) by Recio P, Cuadrado I, and Ramos P, was used [33].

This scale serves to detect sexism regarding traits and attitudes traditionally understood as masculine or feminine. This instrument is a self-completed scale which can be applied collectively. The subject who fills in the questionnaire should respond indicating their degree of agreement with the expression contained in each item on a scale of 1 (Completely disagree) to 6 (Completely agree). In addition, it allows the distinction between traditional hostile sexism and benevolent sexism. It consists of 26 items which should be rated on a scale from 1 (Completely disagree) to 6 (Completely agree) which are grouped by the following aspects. Hostile sexism: Refers to traditional sexism, based on the supposed inferiority of women as a group. Benevolent sexism: Refers to a more concealed type of sexism, expressed through men's intentions to look after women, protect them and adore them and which is also based on an image of women as inferior beings but with a more positive affective quality.

The questionnaires were distributed to 150 publics school students (response rate in the study 100\%), who completed them anonymously and on their own, after receiving an explanation about what the project consisted of and signing the informed consent. In the case of students who were minors, it was the centre, through the teacher, who was responsible for collecting consent from their legal guardians for their participation, after explaining the project to them.

The project began in January 2020. The data collection phase was carried out in the months of May and June. Subsequently, the researchers carried out the statistical analysis phase. The final results were obtained in September 2020.

\section{Results}

There were 150 participants, 74 male (49.35\%) and 76 female $(50.7 \%)$ aged between 12 and 18 years old and from each school year of the secondary school.

Regarding first use of new technologies, the average age of first computer/tablet use was 9.9 years, with a minimum age of 7 and a maximum of 14 years old. However, the minimum age for the first mobile phone use was 3 years old, with a range of 3 to 17 years old and an average of 11.04 .

Regarding content of a sexual nature on the computer, $44 \%$ of students (66) confirmed having viewed it, and of these, $19.3 \%$ (29) used this content regularly, versus $80.7 \%$ who had not done so or who viewed them sporadically or occasionally.

The age of first viewing of a sexual or pornographic nature 
ranged from 7 to 17 years old, with an average of 11.04 years old.

Regarding where these viewings took place, for $26.7 \%$ (40 students) it was in the bedroom versus $9.4 \%$ (14) who viewed them in the living room or dining room of their home (Table 1).

The results of the Scale for detecting sexism in adolescents (Graph 1), for the group total were on average 2.031 (Standard deviation 9.043) for benevolent sexism, 1.43 for hostile sexism (Standard deviation 10.505) and 1.66 for total sexism (Standard deviation 0.693). $43 \%$ of students showed some kind of sexist behaviour versus $57 \%$ who did not show any.

Once calculated, these direct scores can be transformed into assessed scores (percentiles) using tables corresponding to the age and sex of the student who filled in the questionnaire. The scales have been created from a sample of adolescents belonging to the Andalusian region and published by the Regional Government of Andalusia [34] (Table 2).

\begin{tabular}{|c|c|c|c|}
\hline \multicolumn{4}{|c|}{ Vable 1: Descriptive statistics. } \\
\hline Sex: & Men 74 (49.35\%) & Women 76 (50.7\%) & \\
\hline Age: & Minimum: 12 & Maximum:18 & Average: 14.83 \\
\hline $\begin{array}{c}\text { Age of first } \\
\text { computer use }\end{array}$ & Minimum: 7 & Maximum: 14 & Average: 9.9 \\
\hline $\begin{array}{c}\text { Age of first mobile } \\
\text { phone use: }\end{array}$ & Minimum: 3 & Maximum: 17 & Average: 11.04 \\
\hline Internet sex & Yes: $66(44 \%)$ & No: $85(56 \%)$ & \\
\hline Regular sex & Yes 29 (19.3\%) & No 121 (80.7\%) & \\
\hline $\begin{array}{c}\text { Age of first viewing } \\
\text { sexual content }\end{array}$ & Minimum: 7 & Maximum: 17 & Average 11.04 \\
\hline Place of viewing & Bedroom 40 (26.7\%) & Living room 14 (9.4\%) & \\
\hline Benevolent sexism & Average 2.031 & Standard deviation 9.043 \\
\hline Hostile sexism & Average 22.93 (1.43) & Standard deviation 10.505 \\
\hline Total sexism & Average 1.66 & Standard deviation 0.693 \\
\hline
\end{tabular}

Table 2: Types of sexism, results in percentiles by sex and age.

\begin{tabular}{|c|c|c|c|c|}
\hline \multicolumn{2}{|c|}{ Percentiles by age } & Hostile sexism & Benevolent sexism & Total sexism \\
\hline Men & $12-13$ & 20 & 30 & 20 \\
\cline { 1 - 3 } Women & years old & 30 & 20 & 20 \\
\hline Men & $14-15$ & 30 & 30 & 40 \\
\hline Women & years old & 40 & 20 & 20 \\
\hline Men & $16-17$ & 30 & 20 & 20 \\
\hline Women & years old & 30 & 50 & 30 \\
\hline
\end{tabular}

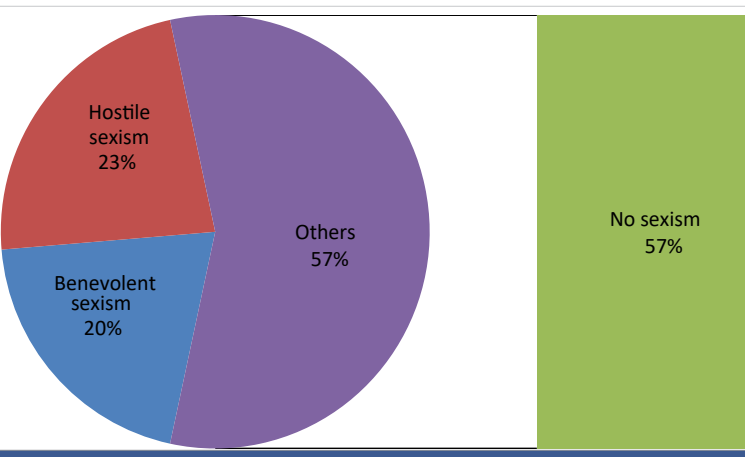

Graph 1: Distribution of kinds of sexist versus non-sexist behaviours.
In these results we observe that the highest percentiles in hostile sexism present in 14-15 year-old females $\left(40^{\text {th }}\right.$ percentile), in benevolent sexism in 16-17 year-old females ( $50^{\text {th }}$ percentile) and in total sexism in 14-15 year old males $\left(40^{\text {th }}\right.$ percentile). The majority of results are on the $20^{\text {th }}$ percentile.

Bivariate correlations were performed in order to establish whether there is any kind of relationship between the variables included in this study, observing a relation between all kinds of sexism and first mobile phone use, in the sense that the adolescents who were younger when they first used it had higher scores in all kinds of sexism. A significant relationship was observed between viewing sexual content and/or pornography and total sexism $(0.163 ; p<0.005)$ and hostile sexism $(0.204 ; p<0.005)$. It was also noted that the greater the score in hostile sexism, the greater the score in benevolent and total sexism (Table 3 ).

\section{Discussion}

Firstly, it should be discussed that the first viewing of sexual content or pornography is situated at seven years old (although with a wide range), a very young age which agrees with the aforementioned authors [1,2]. Conversely, it should be highlighted that first mobile phone use is even younger, and according to our results, this has a significant relationship with the use of sexual content. That is to say, use of sexual content is mostly carried out through the mobile phone and not the computer. Although, the average age of viewing these contents (11.04 years old) agrees with other countries in our setting, such as Italy, the US and Canada $[4,15,17]$.

Our results also confirm that the use of sexual content at young ages favours the appearance of sexist behaviours, as has been observed in other studies [24,25]. As already discussed, by observing aggressive and sexist behaviours and acts in pornography, it may be that they adopt attitudes which support these behaviours, as well as representing them in reality [18], and we have seen how the use of sexual content is significantly associated with total sexism and hostile sexism in our results.

In the detection scale results for the different types of sexism, it stands out that while total sexism is highest in 14 to 15 year-old male students, benevolent sexism is highest in 16 to 17 year-old female students and even stranger is that hostile sexism is highest in 14 to 15 year-old female students. The two aspects which this scale incorporates involve stereotyped and sexist perspectives based on beliefs and attitudes which imply the authority and dominance of the man, granting the woman a dependent role and one of needing protection. High scores in the hostile and benevolent sexism aspects reveal sexist and stereotyped attitudes and a belief that women, as a group, are inferior to men. Whilst high scores in hostile sexism defend this belief through statements of a clearly negative character, high scores in 


\begin{tabular}{|c|c|c|c|c|c|}
\hline & Age of mobile phone use & Viewing sexual content & Total sexism & Benevolent sexism & Hostile sexism \\
\hline Age of mobile phone use & 1 & - & $-0.215^{\star *}$ & $-0.222^{\star \star}$ & $-0.178^{*}$ \\
\hline Viewing sexual content & - & 1 & $-0.163^{*}$ & - & $0.204^{*}$ \\
\hline Total sexism & $-0.215^{\star *}$ & $-0.163^{*}$ & 1 & $0.906^{* *}$ & $0.931^{* *}$ \\
\hline Benevolent sexism & $-0.221^{\star \star}$ & & - & 1 & $0.689^{* *}$ \\
\hline Hostile sexism & $-0.178^{*}$ & $0.204^{*}$ & $0.931^{* *}$ & $0.689^{* *}$ & 1 \\
\hline
\end{tabular}

The younger the mobile phone use, the more sexism. The more sexual content viewed on the internet, the more sexism and hostile sexism

Source: Prepared by the authors, 2020.

benevolent sexism conceal the subordinated perspective of women through supposed affection and protection. Maybe the only possible explanation is that as women mature, the stereotypical belief of a dominant male becomes the benevolent image of a protective male. The second sexist behaviour is much more difficult to identify as such. While at early ages, this use favours the appearance of hostile sexism behaviours as noted in some studies [18].

\section{Conclusion}

Firstly, we believe it is necessary to continue examining this issue, since the use of new technologies is in addition starting at even younger ages due to the situation of online teaching due to the pandemic, and it has been observed that age at first use is a determining factor.

Through other studies, the relationship between use of sexual and/or pornographic contents and mobile phones versus tablets and computers should be confirmed, as tablets and computers do not seem to have a significant relationship with pornography viewing.

It can be stated that the earlier mobile phone use begins, the greater the score in sexist behaviours in general, both hostile and benevolent.

It can also be stated that the more viewings of sexual or pornographic content, the higher the score in sexism and hostile sexism.

No relationship has been found between uses of sexist content or sexist behaviours with computer use.

Lastly, while men score highest in hostile sexism and total sexism, women score highest in hostile sexism at 14-15 years old and in benevolent sexism at 16-17 years old, which leads us to raise the need for them not to confuse benevolent or protective attitudes with this kind of sexism.

\section{Acknowledgment}

This research was sponsored by the University of Jaén, within the SCIENCES 2018 project.

\section{References}

1. Hornor G. Child and Adolescent Pornography Exposure. J Pediatr Health Care. 2020; 191-199.

PubMed: https://pubmed.ncbi.nlm.nih.gov/32063261/
2. Amaia GV, Rubén MA, Lasanta Ruiz de Larramendi S. La pornografía en la adolescencia. Pulso. 2019; 98: 16-19.

3. Charig R, Moghaddam NG, Dawson DL, Merdian HL. A lack of association between online pornography exposure, sexual functioning, and mental well- being. Sex Relatsh Ther. 2020; 0: 1-24.

4. Girouard A, Stulhofer A. A Large-Scale Comparison of Canadian Sexual / Gender Minority and Heterosexual , Cisgender Adolescents' Pornography Use Characteristics. 2020.

5. Landripet I, Bu V, Aleksandar Š. Testing the content progression thesis: A longitudinal assessment of pornography use and preference for coercive and violent content among male adolescents. 2019; 81: 32-41.

6. Dawson K. Adolescent sexual aggressiveness and pornography use : A longitudinal assessment. 2019; 587-597.

7. Binford $W$. Viewing pornography through a children's rights lens. 2019; 25: 415-444.

8. Maas MK, Bray BC, Noll JG. Online Sexual Experiences Predict Subsequent Sexual Health and Victimization Outcomes Among Female Adolescents: A Latent Class Analysis. J Youth Adolesc. 2019; 48: 837-849.

PubMed: https://pubmed.ncbi.nlm.nih.gov/30778831/

9. Vangeel L, Eggermont S, Vandenbosch L. Does Adolescent Media Use Predict Sexual Stereotypes in Adolescence and Emerging Adulthood? Associations with Music Television and Online Pornography Exposure. Arch Sex Behav. 2020; 0123456789.

10. Impacts A. Reasons for Pornography Consumption: Associations with Gender , Psychological and Physical Sexual. Sex Cult. 2018; 22: 48-62.

11. Lim MSC, Agius PA, Carrotte ER, Vella AM, Hellard ME. Young Australians' use of pornography and associations with sexual risk behaviours. 2017; 41: 438-444.

PubMed: https://pubmed.ncbi.nlm.nih.gov/28664609/

12. Heer BA De, Prior S. Hoegh G, Pornography, Masculinity, and Sexual Aggression on College Campuses. J Interpers Violence. 2020. 886260520906186.

PubMed: https://pubmed.ncbi.nlm.nih.gov/32146855/

13. Wright PJ, Sun C, Steffen NJ, Tokunaga RS. Pornography, Alcohol, and Male Sexual Dominance. 2015.

14. Peter J, Valkenburg PM, Adolescents and Pornography: A Review of 20 Years of Research. J Sex Res. 2016; 53: 509-531.

15. Saramago M, Cardoso J, Leal I. Ac ce cr. J Sex Marital Ther. 2019.

16. Rostad WL, Gittins D, Charlie S, Rizzo CJ, Pearlman D, et al. The Association Between Exposure to Violent Pornography and Teen Dating Violence in Grade 10 High School Students. Arch Sex Behav. 2019; 48: 2137-2147.

PubMed: https://pubmed.ncbi.nlm.nih.gov/31309432/

17. Pizzol D, Bertoldo A, Foresta C. Adolescents and web porn: a new era of sexuality. Int J Adolesc Med Health. 2016; 28: 169-173. PubMed: https://pubmed.ncbi.nlm.nih.gov/26251980/

18. Rasmussen K, Family T, Lens I. A Historical and Empirical Review of Pornography and Romantic Relationships : Implications for Family Researchers. 2016; 8: 173-191. 
19. Stella R. Porn culture, embodied experiences and knowledge of sexual practices. 2020.

20. Wright PJ, Tokunaga RS. Men's Objectifying Media Consumption, Objectification of Women, and Attitudes Supportive of Violence Against Women. Arch Sex Behav. 2016; 45: 955-964. PubMed: https://pubmed.ncbi.nlm.nih.gov/26585169/

21. Maes C, Schreurs L, Oosten JMF Van, Vandenbosch L. \#(Me) too much? The role of sexualizing online media in adolescents' resistance towards the metoo-movement and acceptance of rape myths. J Adolesc. 2019; 77: 59-69.

PubMed: https://pubmed.ncbi.nlm.nih.gov/31654849/

22. Wright PJ, Tokunaga RS, Kraus A. A Meta-Analysis of Pornography Consumption and Actual Acts of Sexual Aggression in General Population Studies. 2016; 66: 183-205.

23. Davis AC, Carrotte ER, Hellard ME, Lim MSC. What Behaviors Do Young Heterosexual Australians See in Pornography? A CrossSectional Study. J Sex Res. 2018; 55: 310-319.

PubMed: https://pubmed.ncbi.nlm.nih.gov/29333877/

24. Rodenhizer KAE, Edwards KM. The Impacts of Sexual Media Exposure on Adolescent and Emerging Adults' Dating and Sexual Violence Attitudes and Behaviors: A Critical Review of the Literature. Trauma Violence Abuse. 2019; 20: 439-452.

PubMed: https://pubmed.ncbi.nlm.nih.gov/29333966/

25. Sun C, Bridges A, Johnson JA, Ezzell MB. Pornography and the Male Sexual Script: An Analysis of Consumption and Sexual Relations. Arch Sex Behav. 2016; 45: 983-994.

PubMed: https://pubmed.ncbi.nlm.nih.gov/25466233/

26. Zhou Y, Paul B, Malic V, Yu J. Sexual behavior patterns in online sexually explicit materials: a network analysis. Qual Quant. 2019; 53 : 2253-2271.
27. Baams L, Overbeek G, Rommes E, Aken MAG Van. Perceived Realism Moderates the Relation Between Sexualized Media Consumption and Permissive Sexual Attitudes in Dutch Adolescents. Arch Sex Behav. 2015; 44: 743-754.

PubMed: https://pubmed.ncbi.nlm.nih.gov/25501659/

28. Tomaszewska P, Krahe B. Predictors of Sexual Aggression Victimization and Perpetration Among Polish University Students: A Longitudinal Study. Arch Sex Behav. 2018; 47: 493-505. PubMed: https://pubmed.ncbi.nlm.nih.gov/27543105/

29. Tomic I. Associations Between Croatian Adolescents' Use of Sexually Explicit Material and Sexual Behavior: Does Parental Monitoring Play a Role? 2018; 47: 1881-1893. PubMed: https://pubmed.ncbi.nlm.nih.gov/29071546/

30. Ybarra ML, Thompson RE. Predicting the Emergence of Sexual Violence in Adolescence. Prev Sci. 2018; 19: 403-415. PubMed: https://pubmed.ncbi.nlm.nih.gov/28685211/

31. Davis AC, Temple-Smith MJ, Carrotte E, Hellard ME, Lim MSC. A descriptive analysis of young women's pornography use: a tale of exploration and harm. 2019; 17: 69-76.

PubMed: https://pubmed.ncbi.nlm.nih.gov/31837713/

32. Glick P, Fiske ST. The Ambivalent Sexism Inventory: Differentiating Hostile and Benevolent Sexism. J Personal Soc Psychol. 1996; 70: 491-512.

33. Recio P, Cuadrado I, Ramos E. Propiedades psicométricas de la escala de detección del sexismo en adolescentes. Psicothema. 2007 19: 552-558.

34. Junta de Andalucía. Consejería de Salud. Instrumentos para la evaluación de la salud mental y el desarrollo positivo adolescente y los activos que lo promueven. 2014. 